year 2015, vol. 1, number 1

\title{
ГОДИШНИК
}

\section{ПО БОЛНИЧНА} ФАРМАЦИЯ

FOR HOSPITAL PHARMACY
Официиално издание на
Official publication of professional Organization of Hospital Pharmacists in Bulgaria 


\section{ГЛАВЕН РЕДАКТОР}

доц. маг. фарм. Евгени Григоров, дм

\section{РЕДАКЦИОННА КОЛЕГИЯ}

проф. Златка Димитрова, дфн

проф. Илко Гетов, дф

проф. Георги Момеков, дф

доц. Асена Стоименова, дф

доц. Крум Кафеджийски, дф

д-р Атанас Кундурджиев, дм

маг. фарм. Велина Григорова

\section{EDITOR IN CHIEF}

assoc. prof. Evgeni Grigorov, MScPharm, $\mathrm{PhD}$

\section{EDITORIAL BOARD}

prof. Zlatka Dimitrova, MScPharm, DSc prof. Ilko Getov, MScPharm, PhD

prof. Georgi Momekov, MScPharm, PhD assoc. prof. Assena Stoimenova, MScPharm, PhD assoc. prof. Krum Kafedjiiski, MScPharm, PhD

Atanas Koundurdjiev, MD, PhD

Velina Grigorova, MScPharm

\section{УКАЗАНИЯ ЗА АВТОРИТЕ}

\section{Материалите се отпечатват на български език.}

В списанието се публикуват: Научни статии (до 12 стр.), Обзори (до 12 стр.), Дискусия(до 3 стр.), Позиции (до 2 стр.), Мнения (до 1 стр.), Представяне на нови книги или софтуер (до 1 стр.)

Подаване на ръкописите се извършва единствено в електронен вид (на електронна поща ohpb_us@googlegroups. com или на $\mathrm{CD} /$ дискета в офиса на редакцията).

\section{Изисквания към ръкописа:}

- Заглавие, имена на авторите и месторабота по време на изготвяне на материала на български и английски език

- Име и пълен адрес на кореспондиращия автор, телефон, електронна поща

- Резюме: За научни статии се подготвя резюме със следната структура и подзаглавия: Въведение, Цел, Методи, Резултати и Заключение. При материали без структура (например, методологични материали) се допускат резюмета, неструктурирани по горния начин. Резюмето трябва да съдържа не повече от 250 думи и трябва да е на български и на английски език.

- Ключови думи: Представят се след резюмето на български и на английски език.

Файловете на ръкописа се подават във формат на Microsoft Word. Форматът на страниците трябва да бъде А4 с полета от 2,5 cm от всички страни, шрифтьт 12-point Times New Roman c 1,5 интервал между редовете. Текстът се подравнява само от ляво.

Библиография: Цитираните източници се подреждат и описват непосредствено след основния текст. В текста номерьт на цитирания източник се поставя в скоби. 
МИСИЯ И ЦЕЛ. .5

ИСТОРИЯ НА БОЛНИЧНОТО ДЕЛО И БОЛНИЧНАТА ФАРМАЦИЯ

В БЪЛГАРИЯ

Зл. Димитрова 7

БИОЛОГИЧНИ, БИОТЕХНОЛОГИЧНИ И БИОПОДОБНИ ЛЕКАРСТВЕНИ

ПРОДУКТИ

А. Стоименова и Л. Антонов.

ПРЕГЛЕД И КРИТИЧЕН АНАЛИЗ НА ДАННИ ОТ КЛИНИЧНИ ИЗПИТВАНИЯ

И ЕПИДЕМИОЛОГИЧНИ ПРОУЧВАНИЯ, ДОКАЗВАЩИ СЛОЖНИЯ МОЛЕКУЛЕН

МЕХАНИЗЪМ И ПРОТИВОРЕЧИВА АНТИТУМОРОГЕННА

AКТИВНОСТ НА METFORMIN

Т. Тенева и И. Гетов.

СЬВРЕМЕННИ ПОДХОДИ ПРИ ЛЕЧЕНИЕ НА РАК НА ПИКОЧЕН МЕХУР

О. Антонова и В. Белчева .32

„ОБЩА ОБУЧИТЕЛНА РАМКА” ЗА СЛЕДДИПЛОМНО ОБУЧЕНИЕ

(СПЕЦИАЛИЗАЦИЯ) ПО БОЛНИЧНА ФАРМАЦИЯ

Е. Григоров.

БОЛКАТА В ЕЖЕДНЕВИЕТО, СХВАЩАНИЯ ОТНОСНО АНАЛГЕТИЦИТЕ

И МОДЕЛИ НА ПОВЕДЕНИЕ ПРИ ПОЛЗВАНЕТО ИМ В ЕВРОПА И РУСИЯ:

ЕПИДЕМИОЛОГИЧНО ПРОУЧВАНЕ И АНАЛИЗ

К. И. Ваулъс, Б. Росър, П. Янушевич, Б. Морлиън, С. Еверс и К. Екълстоун 43

ПРЕМИНАВАНЕТО КЪМ УПОТРЕБА НА ГЕНЕРИЧНИ ЛЕКАРСТВЕНИ ПРОДУКТИ: КОНТРОЛНА ПРОВЕРКА НА ВЪПРОСИТЕ ЗА БЕЗОПАСНОСТ

М. Бекер, А. Ф. Й. Ал Хадити, П. М. Л. А. ван ден Бемт и Н. Г. М. Хунфелд .52

ОЦЕНЯВАНЕ НА НЕОБХОДИМОСТТА ЗА КОРЕКЦИЯ НА КОЛИЧЕСТВОТО

НА ЛЕКАРСТВАТА ЗА ПОСТИГАНЕ НА ТОЧНА ДОЗИРОВКА ЗА ДЕЦА

А. Нън, Р. Ричи, У. Шах, К. Баркър, Д. Крейг, М. Пийк, Д. Форд и М. Търнър .57

Адрес на редакцията:

Списание "Годишник по болнична фармация"

Официално издание на ПОБФБ

гр. София 1040

ИНТЕРПРЕД - СТЦ

Бул."Драган Цанков" 36, офис Б 602 ет.6 


\section{O N T E N T S}

AIM AND MISSION

HISTORY OF THE HOSPITAL PRACTICE AND THE HOSPITAL PHARMACY IN BULGARIA

Zl. Dimitrova ......

BIOLOGICAL, BIOTECHNOLOGICAL AND BIOSIMILAR MEDICINAL PRODUCTS

A. Stoimenova and L. Antonov.

OVERVIEW AND CRITICAL ANALYSIS OF CLINICAL TRIALS DATA AND EPIDEMIOL

OGICAL SURVEYS PROVING COMPLEX MECHANISM AND CONTROVERSY

OF ANTI-TUMORIGENIC ACTIVITY OF METFORMIN

T. Teneva and I. Getov

CURRENT APPROACHES IN THE TREATMENT OF BLADDER CANCER

$O$. Antonova and $V$. Belcheva.

“COMMON TRAINING FRAMEWORK" FOR POSTGRADUATE

EDUCATION (SPECIALIZATION) IN HOSPITAL PHARMACY

E. Grigorov

EVERYDAY PAIN, ANALGESIC BELIEFS AND ANALGESIC

BEHAVIOURS IN EUROPE AND RUSSIA: AN EPIDEMIOLOGICAL

SURVEY AND ANALYSIS

K. E Vowles, B. Rosser, P. Januszewicz, B. Morlion, S. Evers and Ch. Eccleston.

SWITCHING TO DIFFERENT GENERIC MEDICINES: A CHECKLIST

FOR SAFETY ISSUES

M. Becker, A. F. Y. Al Hadithy, P. M. L. A. van den Bemt and N. G. Hunfeld

ESTIMATING THE REQUIREMENT FOR MANIPULATION

OF MEDICINES TO PROVIDE ACCURATE DOSES FOR CHILDREN

A. Nunn, R. Richey, U. Shah, C. Barker, J. Craig, M. Peak, J. Ford and M. Turner.

Editorial office address:

Journal „Annual for hospital pharmacy”

Official publication of POHPB

Sofia, 1040

Interpred - WTC

"Dragan Tsankov" 36, blvd., office B 602, floor 6 